\title{
Monolingualism When Practised in a Multilingual Classroom Can Become a Source of Stress to Learners
}

\author{
Dr Stanley Madonsela \\ University of South Africa (UNISA, P O Box 392, Pretoria 0003 \\ Email:madonfs@unisa.ac.za
}

Doi:10.5901/mjss.2014.v5n9p627

\begin{abstract}
The ability to use language is unique from one individual to another. Learners, like many other people, use language to express their feelings, desires and thoughts, but most of all to learn. Classrooms normally consist of learners from different language backgrounds and, therefore, what is happening in the classroom in terms of language used for learning requires rethinking. Interaction in the classroom could maximise the outcomes of learning if the language issue is approached in a manner that confirms the importance of each learner's language. This article explores the extent to which the use of a single code becomes a source of stress in a classroom that is multilingual. It argues that a multingual approach in the learning process can promote learner autonomy in the classroom. The multilingual approach I refer to in this article also affords learners the opportunity to realise the goals of learning and makes it possible for critical intercultural connections amongst learners.
\end{abstract}

Keywords: monolingualism, stress, multilingual, code choice, classroom

\section{Introduction}

In order to understand the frustrations and problems that learners experience with language in the classroom, it is important to understand language as a concept. The situations and environments that learners find themselves in, is changing continually and these changes have a direct effect on the learning that takes place. The fact that most learners in South African classrooms come from different language backgrounds cannot be overlooked if the full purpose of the learning process is to be realised. For a majority of learners in South Africa - and probably in many other countries as well - there are at least two languages involved in the learning process. Limiting this to the South African context, there is English (which is used mostly as a medium of instruction) on the one hand and, on the other hand, a further ten languages that have been declared "official languages" in terms of the South African Constitution. Changes that are taking place in the learner's classroom environment in South Africa and globally in as far as learning is concerned, exert some kind of language pressure which sometimes require "cross-language" approach. The "cross-language" approach in this context refers to the use of more than one language at the same time because of a lack of competency on the part of the learners and/or teachers.

Teaching through a language that learners understand, for example, has the potential to produce good results in the learning process while, conversely, using only a language that is considered foreign to learners can harm such learners' cognitive development and also cause problems for their further progress in life. Besides the cognitive development which could be harmed by the use of one code in the classroom, stress can also takes its toll in such cases. Learners are easily intimidated by their unfamiliarity with a new language and this can cause them stress in an environment where they cannot express themselves with ease in their own language.

\section{Literature Review}

\subsection{The dimension of multilingualism}

Some linguistic theories have assumed monolingualism to be the norm. This is the view that is often held by monolingual individuals such as Edwards (1994) who are speakers of dominant languages such as English. Such a view does not hold any substance in the South African context considering the language complexities that result from the language diversity that prevails here, as well as its policy of multilingualism. In this article the "multicompetent second language learner" theoretical framework based on de Bot, Lowie and Verspoor's (2007) Dynamic Systems Theory (DST) forms part 
of the arguments advanced. Briefly, this framework focuses on an individual's knowledge of a language which includes a first language competence and a developing understanding of a second language. "The multicompetent second-language learner" is the term preferred by scholars such as de Bots over "bilingualism" and "multilingualism". De Bots holds the view that the two terms do not describe the ways in which real people use language. For the purposes of this article, however, these terms will be used interchangeably.

While the focus of this article is not on the theory itself it does, in some cases, explore applicable aspects of the theory. Apart from Dynamic Systems Theory, this article endorses the idea of Herdina and Jessner's (2002) Dynamic Model of Multilingualism (DMM) which considers language as a set of subsystems where multilingualism (rather than monolingualism) is argued as setting the foundation for second language development. When learners listen to a new language that they haven't heard before, they tend to hear a variety of sounds that have no meaning. Learners who already know the language will recognise those sounds and be able to reconstruct them into meaningful language structures. Where learners cannot make sense of the new language they tend to experience stress because communication is impossible and the learning process is compromised.

The teacher in the classroom is expected to take the lead in ensuring that a multilingual approach is adopted in the learning process. With an increasing acceptance of eclectic and critical approaches to language teaching and learning, and of pedagogical implementation of ecological and sociocultural approaches, the time is ripe for the development of a principled, multilingual approach to language in classroom communication (Levine 2011:5). This is the avenue that should be explored in order to ensure that the level of stress related to the language used in the classroom environment is minimised. (Levine 2011:4) echoes the same sentiments in as far as adopting the multilingual approach is concerned as he postulates:

To accomplish these goals, we must develop an approach to treating the language classroom as an authentic social environment in its own right, rather than as an artificial aberration from normal social life, and for promoting learner autonomy by allowing learners a say in the ways code choices are made.

The main purpose of using a multilingual approach, as Levine affirms, is to provide learners with the opportunity to use multiple codes in the classroom learning process. Although there are conflicting views regarding the use one language in multilingual classrooms (because of the belief that the use of English in a foreign language classroom, for example, allows students to discuss multifaceted issues related to language in intellectually stimulating ways), the fact is that such an approach can have its drawbacks in multilingual classrooms. Though the importance of using first language - in order to promote the awareness of second language learning in the learning process - cannot be neglected, there are still questions with regard to the extent to which second language learners are going to learn the target language and become either "competent enough" or become multicompetent second language users. Drawbacks such as stress levels experienced by learners whose language is not the medium of instruction used in the classroom cannot be overlooked.

\subsection{Defining the concept "language"}

The issue of language is sometimes neglected in the learning process and this neglect could have adverse consequences for learners. This article is not about language per se or about the dynamics around it. Rather, it focuses on the use of language to the benefit of the learner. It is for this reason, therefore, that certain definitions of the term are omitted. Many scholars have defined the term "language" differently, basing their definitions on their field of study and the nature of their research. However, for the sake of this article, the definition of the term by Titone \& Danesi (1985) seems appropriate. Their definition of the term language can be summarised as follows:

Language is a communication system by which people are able to express their thoughts. It does not consist of a variety of random series of speech sounds but of language symbols that form a connected set of relationship and patterns.

The above definition of the term "language" affirms the importance of language in the classroom as it is through language that learners can be able to interact in the learning process. Because learners come from different language backgrounds, language can also become a powerful tool able to unite them, especially in multilingual classrooms and in multicultural societies such as South Africa.

What becomes central to the learning process in as far as language is concerned is that it takes places within four cognitive functions as identified by Titone \& Danesi (1985:46). These are i) grouping information according to corresponding features; ii) differentiating between the language stimuli and the object; iii) generalising by classifying the information into categories and; iv) associating the stimuli with the object. In order for these functions to yield positive 
results, Phelps-Terasaki et al (1983:xiv) suggest the learner's "inner language system" which they regard as a representative symbolic thought system. Inner language comes first - before the "real" language - and continues until after the learner has mastered the language structures. The teacher in a multilingual classroom should consider using a multilingual approach in order to accommodate those learners whose home language is not the medium of instruction use in the school. The understanding of the form, content and function of the language by the learner which Richek, List and Lerner (1983), Berko Gleason (1989) and Hallahan and Kauffman (1991) refer to as the dimensions of language, should form the core of the learning process.

\section{What is Stress in a Classroom Environment?}

There have been a number of definitions of the term. However, it has been observed that these definitions tend to fit the situations in which they are used. Hans Selye (1976), who is regarded as the father of stress research, defines stress as the non-specific response of the body to any demand for change. Research reveals that the term was originally used in physics to describe the forces that could cause an object to break or to bend. Now, however, the term is closely associated with the complexities of certain lifestyles that often result in illness or in extreme cases death. In the education environment, the Collins English Dictionary (1991:1527) definition seems relevant as it defines stress as a mental, emotional or physical strain or tension. The mental and emotional aspects of this definition describe especially well the stresses experienced by learners.

The emphasis here is on the mental strain that learners experience because of the use of languages that are foreign to them. It is also possible that such mental and emotional strain results from the demanding learning environment in which learners find themselves in the classroom. Weinstein and Rosen (2003:271) add to the definition of the term, maintaining that stress is frequently used to describe the level of tension resulting from demands of the job, family responsibilities and the complexities of relationships. Stress, then, is not limited to the demands of the job or family responsibilities, but can also extend to the classroom environment and there it can do harm to the learning process. This point should therefore be taken into consideration when code choice is made in the classroom. This view should not be construed in any way as suggesting doing away with the predetermined medium of instruction used in the classroom.

\section{When Does Language-Related Stress Become Detrimental in the Classroom?}

Stress can function in different ways depending on its level and the reaction that comes with it. It can have both positive and negative effects and, in limited amounts, can be helpful sometimes. In certain instances, stress can motivate one to put more effort into whatever one is doing and get things done. It can also be a warning to others to indicate that something is wrong and that a swift response is required in reaction. In the case of language in the classroom, stress can sometimes motivate a learner to learn the language used as the medium of instruction. This could work to the advantage of the learner in that the acquisition of the language used in the classroom is quicker.

Stress can also be harmful at times. In other environments, it can be unpleasant, distractive and sometimes lead to anxiety and to long-term psychological problems. In the case of a classroom situation, if the medium of instruction is not a language that the learner understands properly it can lead to the learner's withdrawal from participation in classroom activities. The problem does not end there; it can also lead to the learner viewing the classroom and the school environment as being unpleasant.

Should this occur, there would be a need for an urgent intervention - especially in the choice of a code that would be accommodative to the learner. In such a situation, the teacher could consider adopting a multilingual approach during the learning process. It is important that the classroom should be an environment in which learners are encouraged to communicate with ease. Along these lines, Edmondson (1985:162) maintains that we seek in the classroom to teach people how to talk when they are not being taught. This approach does not necessarily mean that the classroom should seek to re-create the norms of societal multilingual environments (Cook 2001). The classroom can be another environment that pushes the objectives of multilingualism within the framework of a school environment. Code choice becomes crucial in environments where not all the learners are from the same language background. Levin (2011: 6) echoes these sentiments when commenting on the importance of code choice as follows:

Code choice pervades all sorts of encounters between teacher and students and amongst students, from the first day of introductory instruction through the most advanced levels, and locating cause-effect relationships, or even significant associations, between particular code-switching practices and language gains would always lead back to a focus on other variables.

Code choice seems to be the approach to consider when faced with a situation of a multilingual classroom within a 
monolingual environment. Although the issue of the language used in the classroom can trigger stress in learners, adoption of a multilingual approach seems to be an easy way to deal with the problem. However, it is also equally important to look at the fundamental factors around why learners tend to become stressed in the classroom, especially when language matters are involved.

\section{Monolingualism and Multilingual Classrooms}

Monolingualism is considered to be the ability to speak only one language. In a monolingual classroom, learners speak the same language and, in most cases, also share a cultural background. There is scepticism, though from some scholars, who believe that a multilingual situation can have certain adverse effects on one or more of the languages involved. One of the effects mentioned is that multilingualism can lead to language loss. It is also argued that it sometimes leads to diffusion; that is, the spread of certain features from one language to the other (or others) as a result of the contact situation (Wardhaugh, 2006:100). But is this a reality in most of our classroom environments? The dynamics of multilingualism are such that researchers doing studies on bilingual and multilingual communities around the globe argue for a wide definition that views bilingualism as a common human condition that makes it possible for an individual to function, at some level, in more than one language.

Most scholars on bilingualism and multilingualism, such as Crystal (1987), Baker \& Prys-Jones (1998), Hamers \& Blanc (2000) and Dewaele et al., (2003) note that there are estimated to be far more bilingual and multilingual speakers in the world than there are monolinguals. South Africa falls in line with this observation, especially when its Constitution, which endorses the eleven official languages, is considered. A "monolingual" is regarded by Crystal (1987: 425) as a person or community with only one language. Such a person or community is also referred to as "unilingual". A multilingual person, on the other hand, is a person who can communicate in more than one language and who is also involved actively in speaking and writing, or passively in listening and reading, a language.

The classroom environment in South Africa, and probably in most parts of the world, does not support a monolingual approach. Most scholars such as Belz (2003), Chavez (2003), Liebscher and Dailey-O'Cain (2004), and Levine (2005) have made the observation that the language classroom is a multilingual environment. Despite the fact that several teaching techniques and exercises tend to be common to both monolingual and multilingual classes, one of the important factors that teachers need to consider as fundamental with regard to the language used for instruction is that learners are somehow unable to resist the temptation of turning back to what they logically find easiest, i.e. their language.

It can be difficult to get learners in a monolingual classroom to speak English to each other. There is nothing that compels them to do so and it thus becomes easy for them to communicate in the language that they are comfortable with. This is one factor that cannot simply be dropped as if the problem does not exist. For this reason a multilingual approach that would ensure that language used in the classroom does not lead to mental strain amongst the learners is called for. Levine (2011:36) suggests a set of methodological choices for fostering a multilingual classroom community of practice in a dynamic framework based on regarding classroom communication simultaneously as a local phenomenon and the product of complex social and political factors, driven by a reflexive, critical approach to code choice norms. This view looks at the language factor, even beyond the classroom environment.

Most scholars agree that it is not much more of a challenge to teach in a classroom with learners from many language backgrounds than from only one, and also that it is easier for learners to learn a second language in a multilingual rather than a monolingual classroom. In the South African school environment for example, there may be learners from two language groups, for example, the Nguni and Sotho languages. The level of stress brought about by the introduction of English as a medium of instruction can be minimal as learners will easily identify themselves with their languages. Instead, there will be motivation to learn the second language which, at first, seems foreign to them. In such a case, the second language to them would be English which is also mostly used as the medium of instruction in the classroom. Second language learning requires a lot of motivation and practice and that is possible if learners are surrounded by innate speakers of their own language.

Whilst a multilingual approach and a multilingual classroom reduce the level of mental strain on learners in as far as language learning is concerned, it also reinforces the intercultural communicative competencies in them. What should be known in the learning of a language is that there is also culture involved. It would be a mistake if language were to be separated from culture as culture constitutes language. The acquisition of intercultural communicative competence, as Byram (1997) views it, is the sum of qualities required of the language learner. Scholars such as Kramsch $(1993,2006)$, Byram (1993) and Crozet and Liddicoat (1999) believe that the acquisition of a second language goes beyond simply what is understood and that the learners should achieve a degree of intercultural communicative competence. It is 
through language that learners are able to interact on cultural matters and are able to identify themselves with a particular culture. Although this view could appear not to be in harmony with the idea of learning a language in the learning process, the fact remains that the use of a foreign language in a class that consists of multilingual learners can sometimes become a source of stress. There has to be a balance in the approach used in the classroom in as far as language is concerned.

\section{Conclusion}

Multilingualism has become more the norm than the exception in the South African context and, most probably, throughout the rest of the world. South Africa's diverse society requires that all learners know how to communicate across the permeable linguistic and cultural borders of our communities. The foregoing discussion reveals that taking a multilingual approach in a multilingual classroom is the better option and can also contribute towards minimising (if not eradicating) the stress levels in learners. This approach is also considered in view of the fact that multilingual speakers outnumber monolingual speakers in South Africa, and probably even in the world's population. Apart from the reduction of stress levels that takes place among learners in multilingual classrooms, learners may have similar learning strategies to each other as well as similar problems learning the target language. Learners are likely, then, to feel that they are not alone in such a situation and, as a result, explore avenues to learning the language used for instruction.

\section{References}

Baker, C. and Prys Jones, S. (1998). Encyclopaedia of bilingualism and bilingual education. Clevedon: Multilingual Matters.

Belz, J.A. (2003). Identity, deficiency, and first language use in foreign language education. In Blyth (ed.) The sociolinguistics of foreign-language classrooms: Contributions of the native, the near-native, and the non-native speaker (pp. 209-248). Boston, MA: Heinle.

Berko Gleason, J. (1989). Studying language development. In the development of language, edited by Berko Gleason, J. second edition. Colombus, Ohio: Merrill.

Byram, M. (1997). Teaching and Assessing Intercultural Communicative Competence. Clevedon: Multilingual Matters.

Chavez, M. (2003). The diglossic foreign language classroom. In Blyth (ed.) The sociolinguistics of foreign-language classrooms: Contributions of the native, the near-native, and the non-native speaker (pp. 209-248). Boston, MA: Heinle.

Crozet, C. and Liddicoat, A. (1999). The challenge of intercultural language teaching: Engaging with culture in the classroom. In J. Lo Bianco, C. Crozet and A. Liddicoat (eds) Striving for the third place: Intercultural Competence through Language Education (pp. 113-125). Melbourne: language Australia.

Crystal, D. (1987). The Cambridge encyclopaedia of language. Cambridge: Cambridge University Press.

Collins English Dictionary (1991). 3rd ed. Glasgow: HarperCollins.

Cook, V.J. (2001). Using the first language in the classroom. Canadian Modern Language Review 57 (3), 402-423.

De Bots, K., Lowie, W. and Verspoor, M. (2007). A dynamic systems theory approach to second language acquisition. Bilingualism: Language and Cognition 10 (1), 7-21.

Dewaele, J.M., A. Housen \& L. Wei (eds.) (2003) Bilingualism: Beyond basic principles. Festschrift in honour of Hugo Baetens Beardsmore. Clevedon : Multilingual Matters.

Edmondson, W.J. (1985). Discourse worlds in the classroom and foreign language learning. Studies in second language acquisition 7 (2), 159 168.

Liebscher, G and Dailey-O'Cain, J. (2004). Learner code-switching in the content-based foreign language classroom. Canadian Modern language Review 60 (4), 501-25. Reprinted in The Modern Language Journal 89 (2), 234-47, 2005.

Levin, G.S. (2005). Articulation of code-choice practices in the foreign language classroom. In C. Barrett and K. Paesani (eds) Language Program Articulation: Theoretical and Practical Foundations. Boston, MAL Heinle.

Levin, G.S. (2011). Code choice in the language classroom. Bristol: Multilingual Matters.

Kramsch, C. (1993). Context and Culture in Language Teaching. Oxford: Oxford University Press.

Kramsch, C. (2006). From communicative competence to symbolic competence. The Modern Language Journal 90 (2), $249-252$.

Hallahan, DP. and Kauffman, JM. (1991). Exceptional children: introduction to special education. 5th edition. Eaglewood Cliffs, NJ: prentice-Hall.

Hamers, J. F. \& M.H.A. Blanc (2000). Bilinguality and bilingualism. Second edition. Cambridge: Cambridge University Press.

Herdina, P. \& Jessner, U. (2002). A dynamic model of multilingualism: Perspectives of change in psycholinguistics. Clevedon: Multilingual Matters.

Pavlenko, A. (2000). "L2 influence on L1 in late bilingualism". Issues in Applied Linguistics 11(2), 175-206.

Phelps-Terasaki, D. Phelps-Gunn, T. and Stetson, EG. (1983). Remediation and instruction in language: oral language, reading and writing. London: Aspen.

Richek, MA., List, LK.. \& Lerner, JW. (1983). Reading problems: diagnosis and remediation. Eaglewood Cliffs, NJ: prentice-Hall.

Titone, R. \& Danesi, M. (1985). Applied psycholinguistics: an introduction to the psychology of language learning and teaching. Toronto: University of Toronto Press.

Wardhaugh, R. (2006). An introduction to sociolinguistics. Malden: Blackwell.

Weinstein, E \& Rosen, E. (2003). Teaching children about health. Second edition. Belmont, CA: Wadsworth.

Selye H. (1976). Stress in health and disease. Reading, MA: Butterworth. 